\title{
Effect of Laser Remelting and Simultaneous Application of Ultrasonic Vibrations during Laser Melting on the Microstructural and Tribological Properties of Laser Clad Al-SiC Composites
}

\author{
Sourabh Biswas (D), S. Habib Alavi and Sandip P. Harimkar* \\ School of Mechanical and Aerospace Engineering, Oklahoma State University, Stillwater, OK 74078, USA; \\ Sourabh.Biswas@okstate.edu (S.B.); Habib.Alavi@okstate.edu (S.H.A.) \\ * Correspondence: Sandip.Harimkar@okstate.edu; Tel.: +1-405-744-5830
}

Received: 7 October 2017; Accepted: 1 November 2017; Published: 3 November 2017

\begin{abstract}
Laser composite surfacing of aluminum alloys with ceramic particles has been extensively investigated for improving tribological properties. However, the process often results in incomplete penetration of ceramic particles in the melt pool and undesirable interfacial reactions. In this paper, laser composite surfacing of 2024 aluminum alloy with $\mathrm{SiC}$ particles is investigated using two distinct approaches: laser remelting and laser melting under the influence of ultrasonic vibrations of preplaced powder mixture. Detailed analysis of variation of clad layer thickness, microstructure in the composite clad layer, phase/texture development, surface roughness, and sliding wear performance with laser processing conditions is presented. The analysis showed that remelting and ultrasonic vibration assist results in significant improvement in clad layer thickness and microstructure (reduction in needle-like $\alpha$-Si phase). While the laser remelting resulted in significant reduction in wear rate, the specimens processed with ultrasonic vibration-assisted laser melting showed variable wear rate, likely due to complex effects of microstructural modification and enhanced surface roughness.
\end{abstract}

Keywords: laser surface cladding; Al-SiC composite; wear

\section{Introduction}

Aluminum alloys have gained rapid popularity in the last few decades-especially in automobile and aerospace industries - due to their easy availability, high strength-to-weight ratio, excellent corrosion resistance, and appreciable formability. However, these alloys are often reported to exhibit inadequate surface properties such as wear and corrosion resistance, and thus are often required to be replaced frequently [1]. It should be noted that developing the ceramic particle reinforced surface has been quite successful in addressing the poor wear resistance issues of aluminum alloys [2]. Non-conventional surface processing techniques such as laser composite surfacing/cladding have been reported to be particularly successful in developing ceramic particle reinforced aluminum systems [3]. The success of laser processing techniques in such technologies has been associated with non-contact processing, superior control during the processing, and short processing time [4]. These features, therefore, have been the key for the promising results that include the ability to form comparatively thick coatings (as thick as $1.5 \mathrm{~mm}$ ), metallurgical bonding between the cladded surface and bulk, and relatively small heat affected zones [5].

Wear behavior of laser clad aluminum composite surfaces has been studied in several research endeavors. For instance, marked improvement in cavitation erosion resistance was observed in the laser processed 6061 aluminum alloy surfaces reinforced with $\mathrm{SiC}$ and $\mathrm{Si}_{3} \mathrm{~N}_{4}$ particles [6]. An appreciable improvement in surface hardness has also been reported in the laser composite surfaced 2024 and 
6061 aluminum alloys reinforced with TiC particles [7]. The development of composite surface on 6061 alloy has also been attempted by triggering in situ TiC formation during laser processing [8]. However, in spite of the aforementioned advantages, achieving uniform ceramic particle distribution in the laser clad composite layer is reported to be extremely challenging. For example, laser composite processing was performed on commercially pure aluminum, 6061 and 8090 aluminum alloys, $\mathrm{Mg}$ (WE43), Stellite, and commercially pure titanium using $\mathrm{SiC}$ and $\mathrm{Al}_{2} \mathrm{O}_{3}$ particles [9]. It was reported that considerable undesirable particle movement was present during laser melting for particle-alloy combinations with relatively large differences in density. Similar incomplete penetration of particles has also been observed in laser clad $\mathrm{SiC}$ dispersed aluminum composite [10]. The typical solutions to overcome the shallower penetration of ceramic particles are increasing laser power and increasing the particle injection velocity. Increasing particle injection velocity results in significant loss of molten material due to splashing, while increasing laser power triggers the formation of undesired compounds (such as $\mathrm{Al}_{4} \mathrm{C}_{3}$ in laser clad Al-SiC composites). Hence, investigations on the development of laser composite surfaced specimen by pre-placement of powder (instead of injecting) have also been reported [11]. The laser surface cladding using pre-placed SiC powders for the processing of compositionally graded thin $\mathrm{SiC}$ layers on aluminum substrate has also been demonstrated [12]. However, the issues related to non-uniform distribution of particles in the composite layer and undesirable reactions between the constituents during laser composite surfacing still remain.

In this paper, laser composite surfacing of 2024 aluminum alloy with SiC particles using preplaced composite mixture is investigated. The primary motivation of the study is to improve the microstructure and tribological properties of the lased clad Al-SiC composite surface using two distinct approaches, namely laser remelting and simultaneous application of ultrasonic vibrations during laser melting. The laser remelting of the Al-SiC composite layer is expected to modify the microstructure and distribution of the particles in the composite layer. As ultrasonic vibrations have been proven effective for improving fluid convection and cavitation in the melt $[13,14]$, the application of such vibrations to the surface during laser composite surfacing is also likely to improve the distribution of the particles in the melt. Detailed analysis of the effect of laser remelting and simultaneous application of ultrasonic vibrations during melting on the thickness of composite clad layer, microstructure, phase evolution, and tribological properties is presented.

\section{Materials and Methods}

Commercial 2024 aluminum alloy with a thickness of about $5 \mathrm{~mm}$ was used in this investigation for laser composite cladding using $\mathrm{SiC}$ reinforcement. The aluminum alloy specimens were carefully polished using 1200 grit size paper, sand blasted, and subsequently cleaned with to remove surface impurities. Commercially pure $\mathrm{Al}$ (particle size: $10-14 \mu \mathrm{m}$ ) and $\mathrm{SiC}$ (particle size: $10.6 \mu \mathrm{m}$ ) powder mixture in the 80:20 ratio by weight was ball milled for $15 \mathrm{~min}$ at $300 \mathrm{rpm}$. Subsequently, a slurry of the powder mixture was prepared using water soluble organic binder (LISI W 15853) and reducer (LISI W 15833) and was sprayed on the surface of the AA2024 substrate. The thickness of dried coatings was measured using a 3D profilometer (Model: PS50, Nanovea, Irvine, CA, USA). Each specimen coated with powder mixture was subsequently mounted on an ultrasonic vibration probe/horn (Sonics \& Materials Inc., Newtown, CT, USA). The probe was 1" in diameter and made of Ti-alloy; the probe was activated using a $20 \mathrm{kHz}$ ultrasonic power generator (Sonics \& Materials Inc., Newtown, CT, USA). The probe was turned on for laser melting experiments under the simultaneous application of ultrasonic vibrations. The laser surface melting experiments were performed using a $\mathrm{CO}_{2}$ laser (Ferranti, Manchester, UK) operated in continuous mode at an output power of $900 \mathrm{~W}$ with the focusing distance (WD) fixed at $15 \mathrm{~mm}$. The laser beam had a Gaussian energy distribution and a spot diameter of $2.15 \mathrm{~mm}$. The details of the experimental set-up have been described in the author's previous publication [15]. The laser was scanned on the specimen surface to generate parallel laser track. For remelting, the laser was scanned perpendicular the previous tracks. Four sets of samples, two with and two without simultaneous application of ultrasonic vibrations during laser surface cladding, were processed for laser surface cladding of Al-SiC composites (LM: laser melted; RM: 
laser melted and remelted; ULM: laser melted under the influence of simultaneous influence of ultrasonic vibrations; URM: laser melted and then remelted under the influence of simultaneous influence of ultrasonic vibrations). The laser processing parameters (laser power and scanning speed) and ultrasonic vibration power output/amplitude (in percentage) for the laser melting and remelting experiments are given in Table 1. The wear tests on the laser clad specimens were performed using a ball-on-disc tribometer (Nanovea, Irvine, CA, USA) with $6 \mathrm{~mm}$ diameter $\mathrm{Al}_{2} \mathrm{O}_{3}$ balls to form $4 \mathrm{~mm}$ diameter wear tracks on the samples. A contact load of $10 \mathrm{~N}$ and sliding velocity of $150 \mathrm{rpm}$ was employed for each wear experiment. Each wear test was conducted for a total sliding distance of $100 \mathrm{~m}$, and the weight loss was recorded after the test. A non-contact optical 3D profilometer was used to obtain the surface profiles of the laser surface melted materials. Phase analysis was performed using an X-ray diffractometer operating with $\mathrm{Cu}-\mathrm{K} \alpha$ radiation (PW1830, Philips, Longmont, CO, USA). The microstructural analysis was conducted using a scanning electron microscope (Model: FEI Quanta 600, Thermo Fish Scientific, Hillsboro, OR, USA). The samples were carefully sectioned, polished, and etched using Keller's reagent for microstructure analysis.

Table 1. Processing conditions used for laser surface cladding of 2024 aluminum alloy with SiC.

\begin{tabular}{|c|c|c|c|c|c|}
\hline \multirow{2}{*}{\multicolumn{2}{|c|}{ Processing Conditions Sample ID }} & \multicolumn{2}{|c|}{ Laser Melting } & \multicolumn{2}{|c|}{ Laser Remelting } \\
\hline & & \multirow{2}{*}{$\begin{array}{c}\text { Vibration } \\
\text { Amplitude (\%) }\end{array}$} & \multirow{2}{*}{$\begin{array}{c}\begin{array}{c}\text { Scan Speed } \\
\left(\mathbf{m m} \cdot \mathbf{s}^{-\mathbf{1}}\right)\end{array} \\
10\end{array}$} & \multirow{2}{*}{$\begin{array}{c}\text { Vibration } \\
\text { Amplitude (\%) }\end{array}$} & \multirow{2}{*}{$\begin{array}{c}\begin{array}{c}\text { Scan Speed } \\
\left(\mathrm{mm} \cdot \mathrm{s}^{-1}\right)\end{array} \\
-\end{array}$} \\
\hline Laser processed & LM & & & & \\
\hline without vibrations & $\mathrm{RM}$ & - & 10 & - & 3.33 \\
\hline \multirow{2}{*}{$\begin{array}{l}\text { Laser processed } \\
\text { with vibrations }\end{array}$} & ULM & 80 & 10 & - & - \\
\hline & URM & - & 10 & 80 & 3.33 \\
\hline
\end{tabular}

\section{Results and Discussion}

\subsection{Clad Layer Characteristics}

The microstructures of the laser cladded specimen exhibited the formation of a very distinct composite cladded zone and melt zone. The data for the final clad layer thickness for different samples calculated from cross-sectional scanning electron microscope (SEM) (FEI, Hillsboro, OR, USA) microstructures is presented in Figure 1a. The composite clad layer thickness was about 31.73, 32.57, 39.21, and $60.11 \mu \mathrm{m}$ for LM, RM, ULM, and URM specimens, respectively. Figure $1 \mathrm{~b}$ presents the relative change in the ratio of thickness of the final clad layer $(C)$ to the thickness of initial sprayed powder layer thickness (I). Clearly, significant increase in $C / I$ ratio was observed after remelting operation in the laser processing both with and without simultaneous application of ultrasonic vibrations. The $C / I$ ratio increased from $34.75 \%$ for LM to $57.93 \%$ for RM while it increased from $37.53 \%$ for ULM to $60.11 \%$ for URM specimens. Note that laser melting results in the formation of a dense composite layer on the surface. The subsequent remelting of this dense layer causes further deepening of the laser melted pool and additional mixing of the reinforced particles in the pool, resulting in thicker composite clad layers and higher $C / I$ ratios as observed for RM and URM specimens. The effect of the ultrasonic vibration was also observed to improve the thickness of composite clad layer and $C / I$ ratio in both the melted and remelted specimen. The thickness of the composite clad layer increased from $31.73 \mu \mathrm{m}$ for LM to $39.21 \mu \mathrm{m}$ for ULM while the C/I ratio increased from $34.75 \%$ for LM to $37.53 \%$ for ULM. The composite clad thickness and C/I ratio of $60.11 \mu \mathrm{m}$ and $61.04 \%$, respectively, was observed for URM specimens. It has been widely recognized that ultrasonic vibrations cause cavitation and improve fluid convection in the solidifying melt $[13,16]$. The effects of ultrasonic vibration assistance have been utilized for grain refinements in the castings [17]. It appears that similar effects cause deeper penetration of ceramic particles in the melt pool during laser composite surfacing, resulting in thicker clad layer thickness and improved $C / I$ ratio in specimens laser melted and remelted with simultaneous assistance of ultrasonic vibrations. 

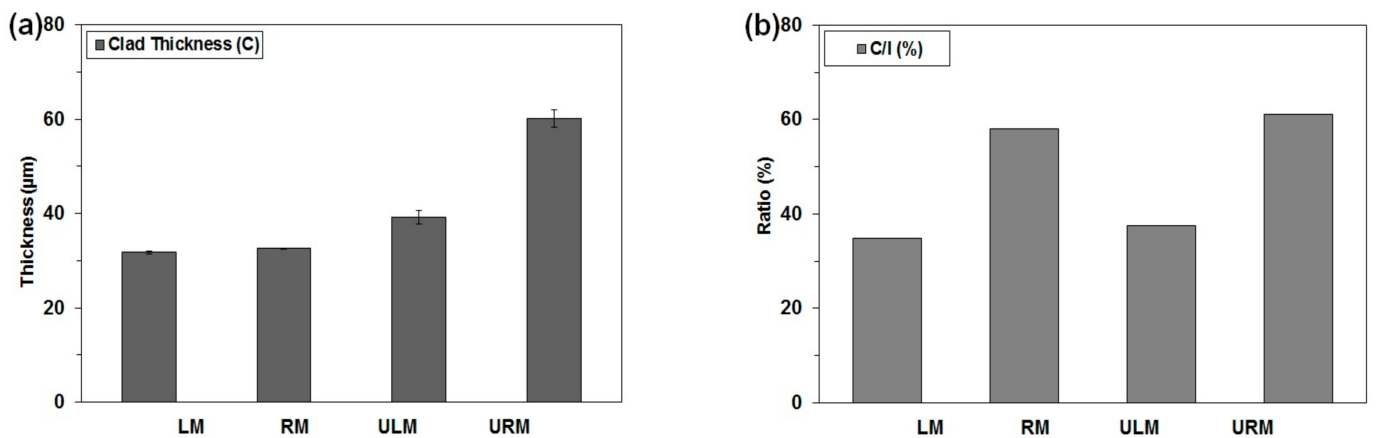

Figure 1. Variation of (a) composite clad layer thickness $(C)$ and (b) ratio of clad layer thickness to initial preplaced powder thickness $(C / I)$ with laser processing conditions.

\subsection{XRD Characterization}

X-ray powder diffraction (XRD) patterns from the surface of the laser clad Al-SiC composite specimens are presented in Figure 2a. While the patterns from all the specimens exhibited characteristic peaks of $\alpha-\mathrm{Al}$ and $\mathrm{SiC}$, some variation in the intensity of peaks was observed. To study the evolution of texture in the specimens, the texture coefficient (TC) was estimated using characteristic peaks of $\alpha$-Al, according to [18]

$$
T C_{h k l}=\frac{I(h k l)}{I_{0}(h k l)}\left\{\frac{I}{n} \sum_{1}^{n} \frac{I(h k l)}{I_{0}(h k l)}\right\}^{-1}
$$

where, $I(h k l)$ is the observed relative intensity of a specific $(h k l)$ peak, $I_{0}(h k l)$ is the relative intensity of standard ( $h k l$ ) peak of pure $\mathrm{Al}$ (JCPDS: 04-0787), and $n$ is the number of diffraction peaks considered in the calculations.

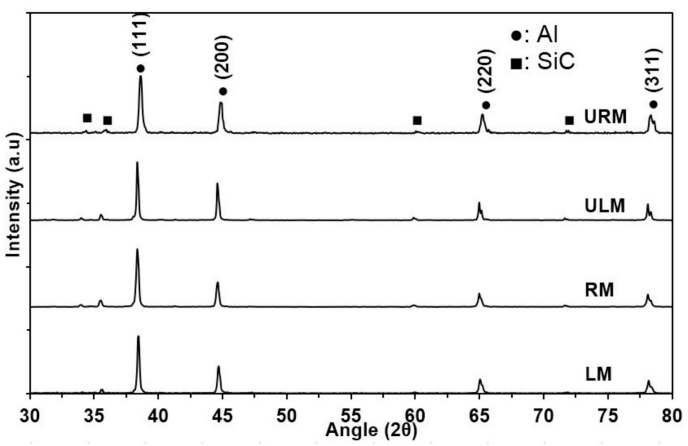

(a)

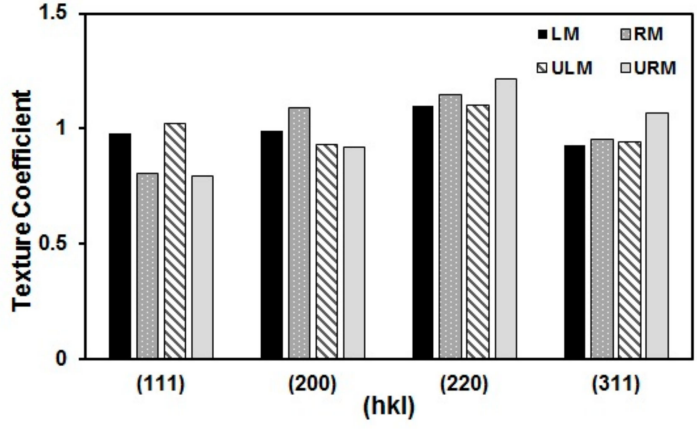

(b)

Figure 2. (a) X-ray powder diffraction (XRD) patterns and (b) texture coefficients for laser clad Al-SiC composite surfaces processed with different laser processing conditions.

The texture coefficients for the all the laser clad Al-SiC surfaces for different crystallographic planes are presented in Figure $2 \mathrm{~b}$. It should be noted that while the resolidified microstructure under the composite clad layer exhibited the typical cellular dendritic grains, the clad layer of the treated specimens exhibited very restricted texturing, suggesting limited opportunity for preferential solidification. It appears that reinforced $\mathrm{SiC}$ particles in the composite clad layer restrict the development of preferential texture in the surface. For example, the TC was estimated to be about 0.92 for (3 1 1) plane and about 1.1 for (2 20 ) plane for specimen LM specimens, indicating random texture. The specimens laser clad with the simultaneous application of ultrasonic vibrations (ULM) also exhibited similar texture coefficients ( 0.94 for ( 311 ) plane and about 1.1 for $(220)$ plane). It is 
expected that the cavitation and enhanced convection in melt pool due to application of ultrasonic vibrations during laser melting, in addition to the presence of $\mathrm{SiC}$ particles, severely restrict grain growth and retain random texture in ULM specimens. However, the laser clad composite surfaces processed by laser remelting (RM and URM) exhibited slightly higher texture coefficients. For example, texture coefficients for (2 20 ) plane were estimated to be 1.14 and 1.21 for RM and URM, respectively. The results indicate that laser remelting, both with and without simultaneous application of ultrasonic vibrations, results in slightly higher texturing compared to laser specimens.

\subsection{Microstructural Characterization}

As mentioned earlier, the laser processing resulted in the formation of a very distinct composite clad layer at the top surface and thicker resolidified zone underneath the clad layer, as presented in Figure 3.

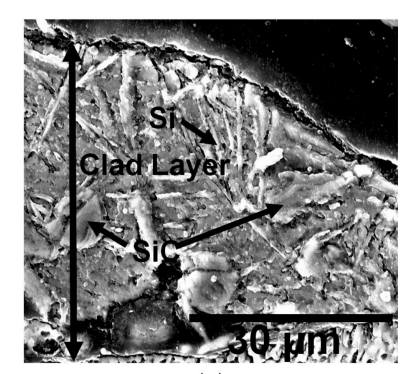

(a)

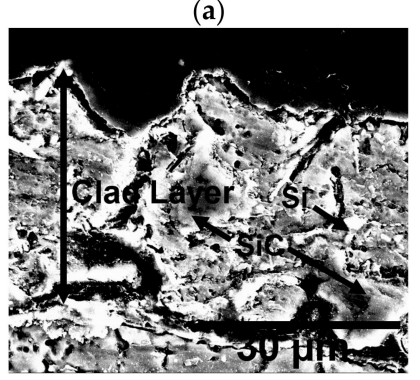

(c)

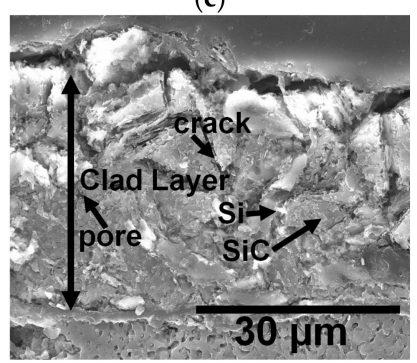

(e)

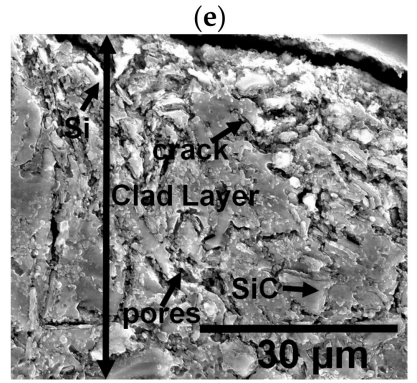

(g)

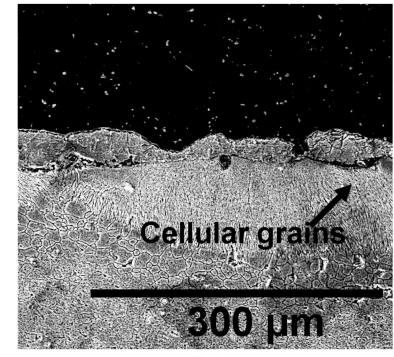

(b)

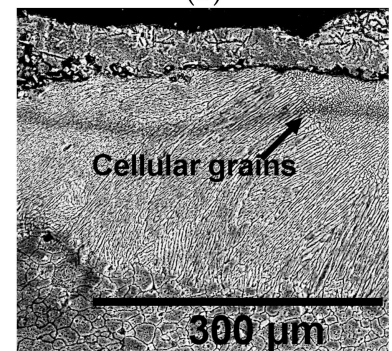

(d)

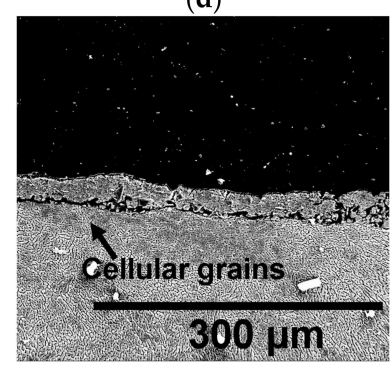

(f)

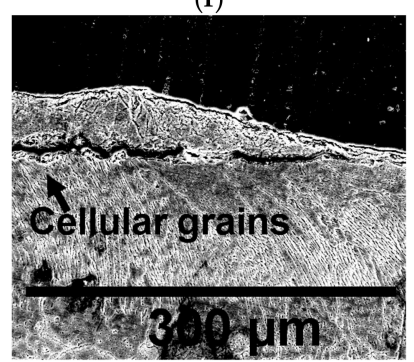

(h)

Figure 3. Scanning electron micrographs from laser clad Al-SiC composite surfaces: (a,b) laser melted (LM); (c,d) laser melted and remelted (RM); (e,f) laser melted under the influence of simultaneous influence of ultrasonic vibrations (ULM); and (g,h) laser melted and then remelted under the influence of simultaneous influence of ultrasonic vibrations (URM). 
The resolidified melt zone thickness of about 150-200 $\mu \mathrm{m}$ was observed for all the specimens. The resolidified zone exhibited typical epitaxial cellular/dendritic morphology characteristic of rapid solidification observed in laser processing [19]. The SiC particles penetrated only near the surface of the melt pool, forming a distinct composite clad layer at the top. The higher magnification microstructures of the composite clad layer for different processing conditions are also presented in Figure 3. The microstructures of the laser clad zone revealed the presence of an acicular needle-like phase. The formation of needle-like phase is a common feature in laser surface engineering of $\mathrm{Al}-\mathrm{SiC}$ composites and has been widely reported to be a eutectic acicular $\alpha$-Si phase [20-22]. Also, the acicular $\alpha$-Si phase is observed to nucleate from the $\mathrm{SiC}$ particles [23]. The microstructures also exhibited presence of pores and microcracks that appeared to be more pronounced in the samples processed under the influence of ultrasonic vibrations due to cavitation effects. While the acicular $\alpha$-Si phase is observed for all the specimens, the composite layers clad with remelting, both with and without application of ultrasonic vibrations (RM and URM), showed marked reductions in the relative percentage of this phase compared to the specimens processed by just laser melting (LM and ULM). It appears that the remelting of the laser clad layer causes partial melting of the needle-like phase formed during initial melting step. Also, the specimens processed with the simultaneous application of ultrasonic vibrations (ULM and URM) showed some reduction of needle-like phase. The application of ultrasonic vibrations during laser melting appears to suppress the interfacial reactions and decomposition of $\mathrm{SiC}$, possibly due to cavitation and enhanced fluid convection.

\subsection{Tribological Analysis}

The wear rates of the laser clad Al-SiC composite surfaces processed with laser melting and remelting, both with and without the simultaneous influence of ultrasonic vibrations, are presented in Figure 4. The laser remelted specimens processed with both the conditions (i.e. without and with simultaneous application of ultrasonic vibrations) exhibited marked improvement in wear resistance. For example, the total wear loss decreased from $2.87 \mu \mathrm{g} \cdot \mathrm{N}^{-1} \cdot \mathrm{m}^{-1}$ for LM to $0.7 \mu \mathrm{g} \cdot \mathrm{N}^{-1} \cdot \mathrm{m}^{-1}$ for RM while it decreased from $2.07 \mu \mathrm{g} \cdot \mathrm{N}^{-1} \cdot \mathrm{m}^{-1}$ for ULM to $1.07 \mu \mathrm{g} \cdot \mathrm{N}^{-1} \cdot \mathrm{m}^{-1}$ for URM specimens. On the other hand, the effect of ultrasonic vibrations on the wear rate was not consistent. The application of ultrasonic vibration during laser processing was observed to improve the wear resistance for laser melted specimens. The wear rate decreased from $2.87 \mu \mathrm{g} \cdot \mathrm{N}^{-1} \cdot \mathrm{m}^{-1}$ for $\mathrm{LM}$ to $2.07 \mu \mathrm{g} \cdot \mathrm{N}^{-1} \cdot \mathrm{m}^{-1}$ for ULM specimens. For the laser remelted specimens, the application of ultrasonic vibrations resulted in a slight increase in wear rate $\left(0.7 \mu \mathrm{g} \cdot \mathrm{N}^{-1} \cdot \mathrm{m}^{-1}\right.$ for $\mathrm{RM}$ to $1.07 \mu \mathrm{g} \cdot \mathrm{N}^{-1} \cdot \mathrm{m}^{-1}$ for URM). As discussed in the previous section, the laser remelting and ultrasonic vibration assist in microstructural modification in the composite clad composite layer, especially the reduction in needle-like $\alpha$-Si phase. It is well recognized that needle-like $\alpha$-Si phase increase the brittleness of the material and is detrimental to the wear performance. The marked reduction in the wear rate for remelted specimens (RM and URM) appears to be partly due to microstructural modification characterized by reduction in needle-like $\alpha$-Si phase.

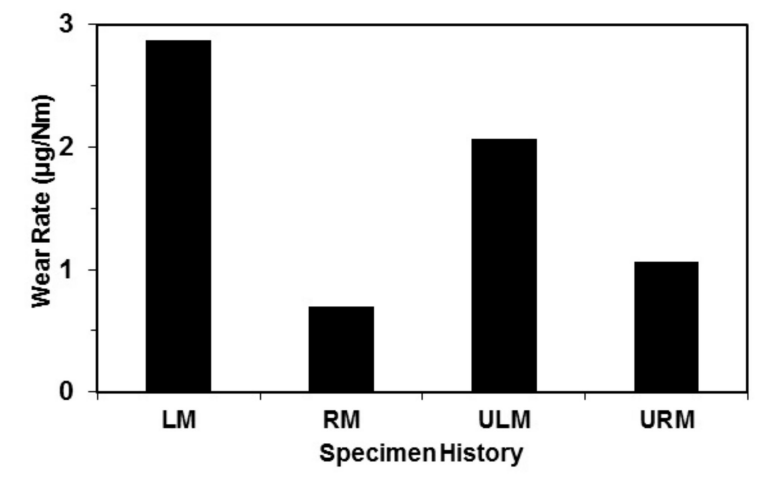

Figure 4. Total wear rate for laser clad Al-SiC composite surface processed with different laser processing conditions. 
As wear performance is also influenced by surface features of the specimens, surface roughness $(R z)$ of the laser clad Al-SiC composite specimens was also characterized (Figure 5). In the specimens laser processed without simultaneous application of ultrasonic vibrations, the laser remelting resulted in reduction in surface roughness (from $53 \mu \mathrm{m}$ for LM to $44 \mu \mathrm{m}$ for RM). Such an improvement in surface finish has likely contributed to a marked reduction in wear rate observed for RM specimens. It should be noted that superior surface finish has often been reported to improve tribological properties [24,25]. On the other hand, laser melting and remelting under the influence of ultrasonic vibrations resulted in slightly higher surface roughness. The surface roughness was observed to be $49 \mu \mathrm{m}$ and $60 \mu \mathrm{m}$ for ULM and URM specimens, respectively. The higher surface roughness of ULM and URM specimens is a direct result of melt cavitation and turbulence in melt pool during laser melting and remelting under the influence of ultrasonic vibrations. This effect of ultrasonic vibrations on melt pool instability during laser melting is well reported in literature. In spite of some microstructural modifications, the higher surface roughness in the ULM and URM specimens resulted in inconsistent wear performance.

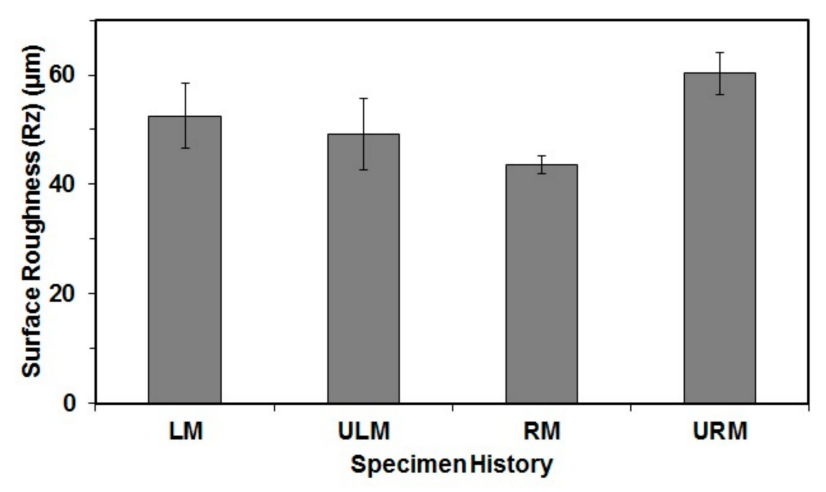

Figure 5. Surface roughness $\left(R_{z}\right)$ of laser clad Al-SiC composite surface processed with different laser processing conditions.

Figure 6 presents the scanning electron micrographs of the wear tracks of the laser clad Al-SiC surfaces processed with different processing conditions. It can be observed from Figure $6 \mathrm{a}-\mathrm{h}$ that deep grooves are present on the wear tracks of all the samples. It has been widely confirmed that the grooves are exclusively associated with the plowing mechanism of abrasive wear $[5,26]$. Also, since mass loss during wear is predominantly caused by abrasive wear, the occurrence of abrasive wear can be deducted for the laser clad composite surfaces. Obviously, the high hardness of the counterbody $\left(\mathrm{Al}_{2} \mathrm{O}_{3}\right)$ as well as the abrasive action of the $\mathrm{SiC}$-rich wear debris from the composite clad layers are the primary causes for the abrasive wear. In addition to deep grooves indicative of abrasive wear, discontinuous patches were also observed on the wear tracks. The presence of such patches indicates that material removal during wear did not proceed through a very continuous regular rate but was irregular, with certain patches undergoing extensive plastic deformation followed by plastic rupture. Similar deformation patches in wear process were also observed in the wear experiments on laser surface cladded Al-SiC specimens [5]. It was reported that the total area of such patches increases at higher loads, and it is also accompanied with an increase in the coefficient of friction. The plastic deformation as well as material removal in patches due to cold welding of the counterbody and substrate material are reported to be common features of an adhesive mode of wear. Hence, the overall wear in laser clad Al-SiC composite surfaces was essentially due to a combination of both adhesive and abrasive mechanisms. 


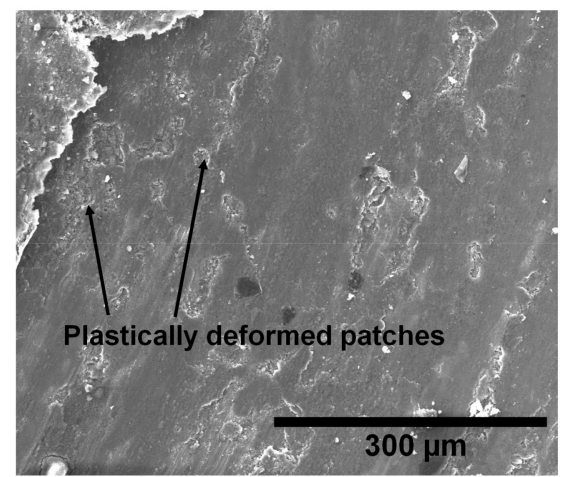

(a)

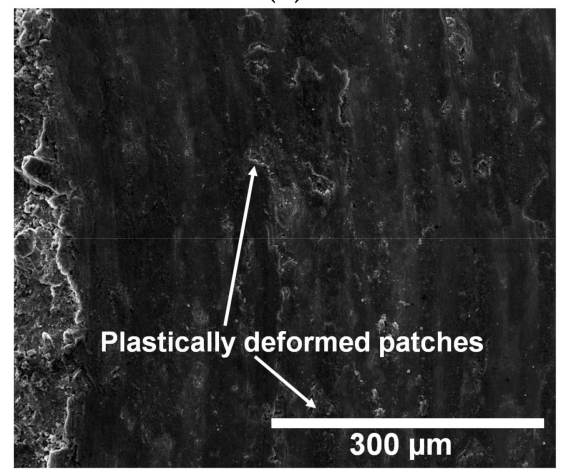

(c)

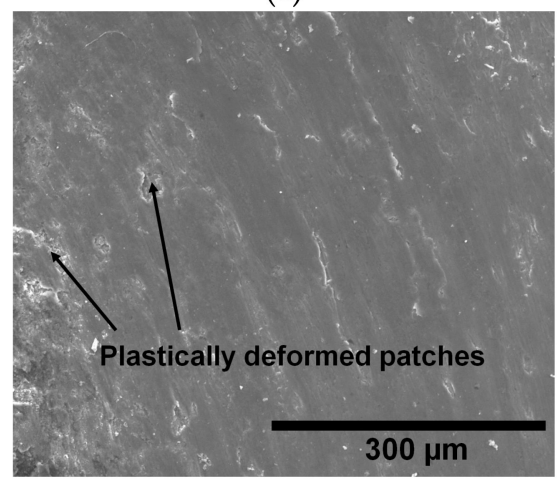

(e)

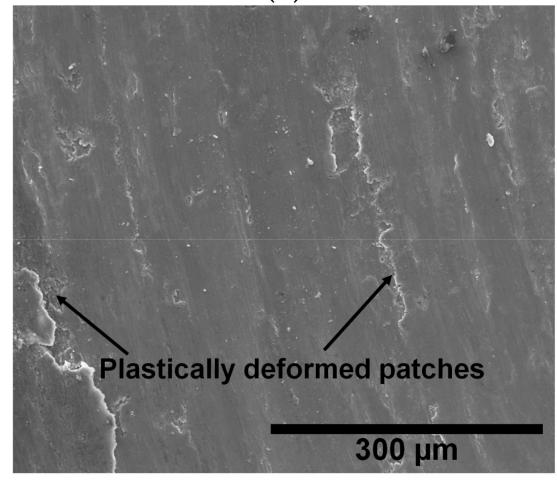

(g)

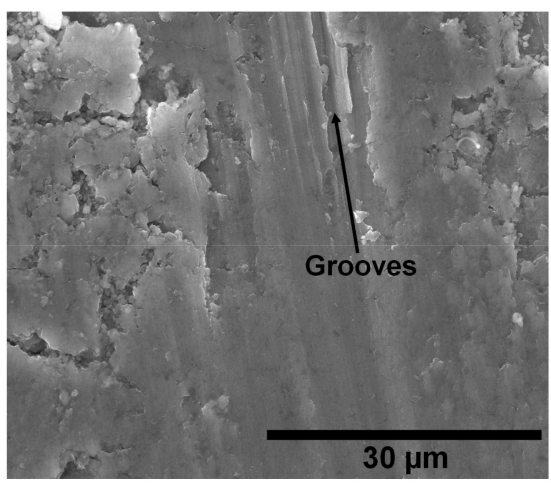

(b)

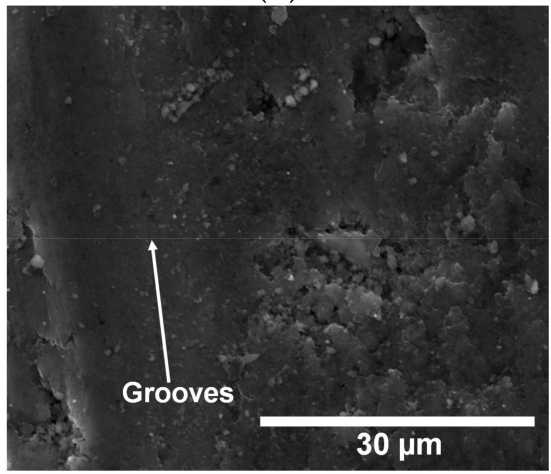

(d)

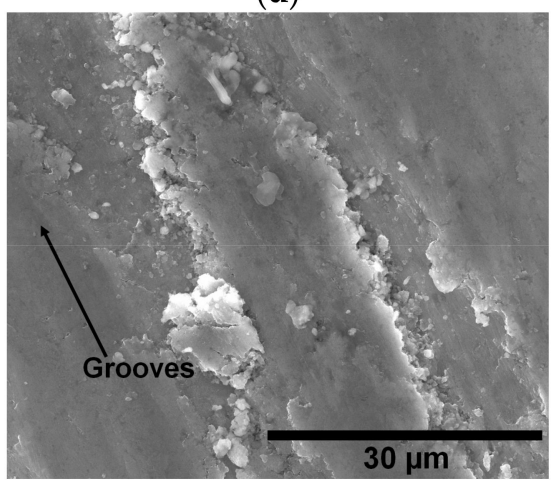

(f)

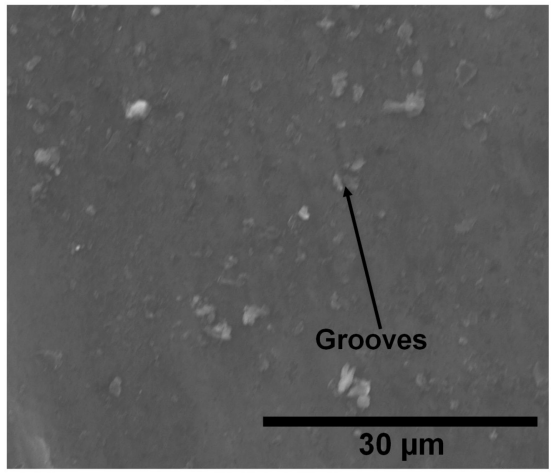

(h)

Figure 6. Low and higher magnification microstructures of wear surfaces of laser clad Al-SiC composites: (a,b) laser melted (LM); (c,d) laser melted and remelted (RM); (e,f) laser melted under the influence of simultaneous influence of ultrasonic vibrations (ULM); and (g,h) laser melted and then remelted under the influence of simultaneous influence of ultrasonic vibrations (URM). 


\section{Conclusions}

The effect of laser melting and remelting, both without and with the simultaneous application of ultrasonic vibrations during laser processing, on the microstructure development and wear properties of Al-SiC clad composite surfaces was investigated. The laser remelting and application of ultrasonic vibrations resulted in an improvement in thickness of laser clad composite surfaces and also a reduction in needle-like $\alpha$-Si phase in the composite microstructure. It appears that the observed microstructural modification is due to partial melting/dissociation of already formed phases during subsequent laser remelting. The similar microstructural modification during ultrasonic vibration-assisted laser melting is likely due to cavitation and enhanced fluid convection effects. While laser remelting resulted in an improvement in surface finish, the specimens processed with ultrasonic vibration-assisted laser melting exhibited higher surface roughness due to melt pool instability. A remarkable improvement in wear resistance of the Al-SiC composites was observed after laser remelting, and the wear mechanisms were characterized by the presence of deep grooves (abrasive wear) and severely deformed patches (adhesive wear). The specimens processed with ultrasonic vibration-assisted laser melting showed inconsistent wear rates likely due to complex effects such as microstructural modification and enhanced surface roughness.

Acknowledgments: This material is based upon work supported by the National Science Foundation under Grant No. CMMI-1149079.

Author Contributions: S.B. and S.H.A conceived and designed the experiments; S.B. and S.H.A. performed the experiments; S.B., S.H.A., and S.P.H. analyzed the data; S.B. and S.P.H. wrote the paper.

Conflicts of Interest: The authors declare no conflict of interest.

\section{References}

1. Wan, Y.; Xue, Q. Effect of phosphorus-containing additives on the wear of aluminum in the lubricated aluminum-on-steel contact. Tribol. Lett. 1996, 2, 37-45. [CrossRef]

2. Davis, J.R. Surface Engineering for Corrosion and Wear Resistance; ASM International: Materials Park, OH, USA, 2001.

3. Rehn, L.E.; Picraux, S.; Wiedersich, H. Surface alloying by Ion, Electron and Laser Beams; ASM International: Metals Park, OH, USA, 1986.

4. Dahotre, N.B.; Harimkar, S. Laser Fabrication and Machining of Materials; Springer Science \& Business Media: New York, NY, USA, 2008.

5. Majumdar, J.D.; Chandra, B.R.; Manna, I. Friction and wear behavior of laser composite surfaced aluminium with silicon carbide. Wear 2007, 262, 641-648. [CrossRef]

6. Man, H.; Kwok, C.; Yue, T. Cavitation erosion and corrosion behaviour of laser surface alloyed MMC of SiC and $\mathrm{Si}_{3} \mathrm{~N}_{4}$ on Al alloy AA6061. Surf. Coat. Technol. 2000, 132, 11-20. [CrossRef]

7. Kadolkar, P.; Dahotre, N.B. Variation of structure with input energy during laser surface engineering of ceramic coatings on aluminum alloys. Appl. Surf. Sci. 2002, 199, 222-233. [CrossRef]

8. Man, H.; Zhang, S.; Cheng, F.; Yue, T. In situ synthesis of tic reinforced surface MMC on Al6061 by laser surface alloying. Scr. Mater. 2002, 46, 229-234. [CrossRef]

9. $\mathrm{Hu}, \mathrm{C} . ;$ Barnard, L.; Mridha, S.; Baker, T. The role of $\mathrm{SiC}$ particulate and $\mathrm{Al}_{2} \mathrm{O}_{3}$ (saffil) fibers in several alloys during the formation of in situ MMCs developed by laser processing. J. Mater. Process. Technol. 1996, 58, 87-95. [CrossRef]

10. Vreeling, J.; Ocelık, V.; Pei, Y.; van Agterveld, D.T.L.; De Hosson, J.T.M. Laser melt injection in aluminum alloys: On the role of the oxide skin. Acta Mater. 2000, 48, 4225-4233. [CrossRef]

11. Gingu, O.; Mangra, M.; Orban, R. In-situ production of Al/SiCp composite by laser deposition technology. J. Mater. Process. Technol. 1999, 89, 187-190. [CrossRef]

12. Majumdar, J.D.; Chandra, B.R.; Nath, A.; Manna, I. Compositionally graded SiC dispersed metal matrix composite coating on Al by laser surface engineering. Mater. Sci. Eng. A 2006, 433, 241-250. [CrossRef]

13. Liu, X.; Osawa, Y.; Takamori, S.; Mukai, T. Grain refinement of AZ91 alloy by introducing ultrasonic vibration during solidification. Mater. Lett. 2008, 62, 2872-2875. [CrossRef] 
14. Biswas, S.; Alavi, S.H.; Harimkar, S.P. Laser surface melting of Ti-6Al-4V under the influence of ultrasonic vibrations. Mater. Lett. 2015, 159, 470-473. [CrossRef]

15. Biswas, S.; Allison, S.; Alavi, S.H.; Harimkar, S.P. Effect of simultaneous application of ultrasonic vibrations during laser surface melting on electrochemical properties of 2024 aluminum alloy. Adv. Mater. Proc. 2017, 2, 675-678.

16. Legay, M.; Gondrexon, N.; Le Person, S.; Boldo, P.; Bontemps, A. Enhancement of heat transfer by ultrasound: Review and recent advances. Int. J. Chem. Eng. 2011, 2011, 670108. [CrossRef]

17. Jian, X.; Xu, H.; Meek, T.; Han, Q. Effect of power ultrasound on solidification of aluminum A356 alloy. Mater. Lett. 2005, 59, 190-193. [CrossRef]

18. Harimkar, S.P.; Dahotre, N.B. Crystallographic and morphological textures in laser surface modified alumina ceramic. J. Appl. Phys. 2006, 100, 024901. [CrossRef]

19. Li, R.; Ferreira, M.G.S.; Almeida, A.; Vilar, R.; Watkins, K.G.; McMahon, M.A.; Steen, W.M. Localized corrosion of laser surface melted 2024-T351 aluminium alloy. Surf. Coat. Technol. 1996, 81, 290-296. [CrossRef]

20. Simchi, A.; Godlinski, D. Effect of sic particles on the laser sintering of Al-7Si-0.3 Mg alloy. Scr. Mater. 2008, 59, 199-202. [CrossRef]

21. Ehrström, J.; Kool, W. Production of rapidly solidified Al/SiC composites. J. Mater. Sci. 1988, 23, 3195-3201. [CrossRef]

22. Anandkumar, R.; Almeida, A.; Colaço, R.; Vilar, R.; Ocelik, V.; De Hosson, J.T.M. Microstructure and wear studies of laser clad Al-Si/SiC (p) composite coatings. Surf. Coat. Technol. 2007, 201, 9497-9505. [CrossRef]

23. Wang, W.; Ajersch, F.; Löfvander, J. Si phase nucleation on SiC particulate reinforcement in hypereutectic Al-Si alloy matrix. Mater. Sci. Eng. A 1994, 187, 65-75. [CrossRef]

24. Jiang, J.; Arnell, R. The effect of substrate surface roughness on the wear of dlc coatings. Wear 2000, 239, 1-9. [CrossRef]

25. Guha, D.; Chowdhuri, S.R. The effect of surface roughness on the temperature at the contact between sliding bodies. Wear 1996, 197, 63-73. [CrossRef]

26. Gandra, J.; Vigarinho, P.; Pereira, D.; Miranda, R.; Velhinho, A.; Vilaça, P. Wear characterization of functionally graded Al-SiC composite coatings produced by friction surfacing. Mater. Des. 2013, 52, 373-383. [CrossRef]

(C) 2017 by the authors. Licensee MDPI, Basel, Switzerland. This article is an open access article distributed under the terms and conditions of the Creative Commons Attribution (CC BY) license (http:/ / creativecommons.org/licenses/by/4.0/). 